\title{
Immune response to fungi in diabetic patients with invasive fungal rhinosinusitis
}

\author{
Thwe Phyo Kan Nyunt, ${ }^{1,2}$ Joaquim Mullol, ${ }^{3}$ Kornkiat Snidvongs ${ }^{1,2}$
}

\begin{abstract}
This article aims to review the literature regarding the immune response to fungi in diabetic patients with invasive fungal rhinosinusitis. Systematic searches of Medline, EMBASE, and Cochrane Library databases were performed to include articles from 1988 to 2019 which assessed 'immune response to fungi in normal host', 'immune deficiency in diabetes mellitus', or 'immune response to fungi in diabetic patients'. Fungal cell wall activated pattern recognition receptors, resulting in recruitment of innate immune cells and an adaptive immune response. In diabetes mellitus, the expression of class I major histocompatibility complex was reduced. A hyperglycemic state decreased vascular dilation and the formation of neutrophil extracellular traps. The structure of complement was altered with consequent inhibition of complement fixation to bacteria. The balance between complement activation and restriction was broken. Hyperglycemia activated protein kinase $\mathrm{C}$ which inhibited neutrophil migration, decreased production of polymorphonuclear cells, decreased chemotaxis and decreased phagocytic activity. Germination and filamentous growth of the fungus within a diabetic host caused angioinvasion, vascular thrombosis and necrosis. Patients with diabetic ketoacidosis had elevated levels of serum iron which regulated endothelial cell damage. Iron and the overexpression of glucose-induced glucose-regulated protein 78 enhanced the susceptibility of endothelial cells to fungi and induced fungal invasion. In summary, associations among the immunopathology of diabetes, the pathophysiology of fungal infections, and the therapeutic outcomes must be considered in clinical practice. In diabetic patients, both the humoral and cellular immune responses of innate and adaptive immune systems were defective. Treatments should aim for the immune function restoration.
\end{abstract}

Key words: diabetes mellitus, fungi, rhinosinusitis, neutrophils, immune response

From:

${ }^{1}$ Department of Otolaryngology, Faculty of Medicine,

Chulalongkorn University, Bangkok 10330, Thailand

2 Endoscopic Nasal and Sinus Surgery Excellence Center,

King Chulalongkorn Memorial Hospital, Bangkok 10330, Thailand

Rhinology Unit et Smell Clinic, ENT Department, Hospital Clinic,

Universitat de Barcelona, IDIBAPS, CIBERES. Barcelona,

Catalonia, Spain

\section{Introduction}

There are over 300 fungal species that are human pathogens. ${ }^{1}$ Patients with immune deficiency are more susceptible to infections, including fungal infections. Mucormycosis is an invasive infection caused by fungi of the class Zygomycetes. ${ }^{2}$ Aspergillosis is an airborne fungus that does not cause a disease in normal or healthy hosts but could cause a serious infection in an immunocompromised host. ${ }^{3}$ Invasive fungal rhinosinusitis is an aggressive and fatal infection. In patients with a defective immune system, invasive fungal rhinosinusitis results from spore germination and tissue invasion. Fever, facial pain, colored nasal discharge and orbital complaints are the most initial presenting symptoms. The clinical presentations of the disease can be quite variable. However, the rapid

\section{Corresponding author:}

Kornkiat Snidvongs

Faculty of Medicine, Chulalongkorn University, Pathumwan,

Bangkok 10330, Thailand

E-mail: drkornkiat@yahoo.com

progression is always characteristic of this disease. Rapid spread into the nearby structures is common. Severe endothelial damage results in extensive necrosis and angioinvasion (Figure 1). The extensions into the orbit, intracranial and the cavernous sinus are the most common complications (Figure 2). Early diagnosis and prompt treatment are mandatory.

The prevalence of invasive fungal rhinosinusitis is high in the immunocompromised patients, such as those with diabetes mellitus, hematological malignancy and those undergoing long-term corticosteroid therapy. Patients with diabetes mellitus are known to be susceptible to infections throughout the entire body. Diabetic ketoacidosis (DKA) can cause a rapid progression of invasive fungal sinusitis due to 
APJAI

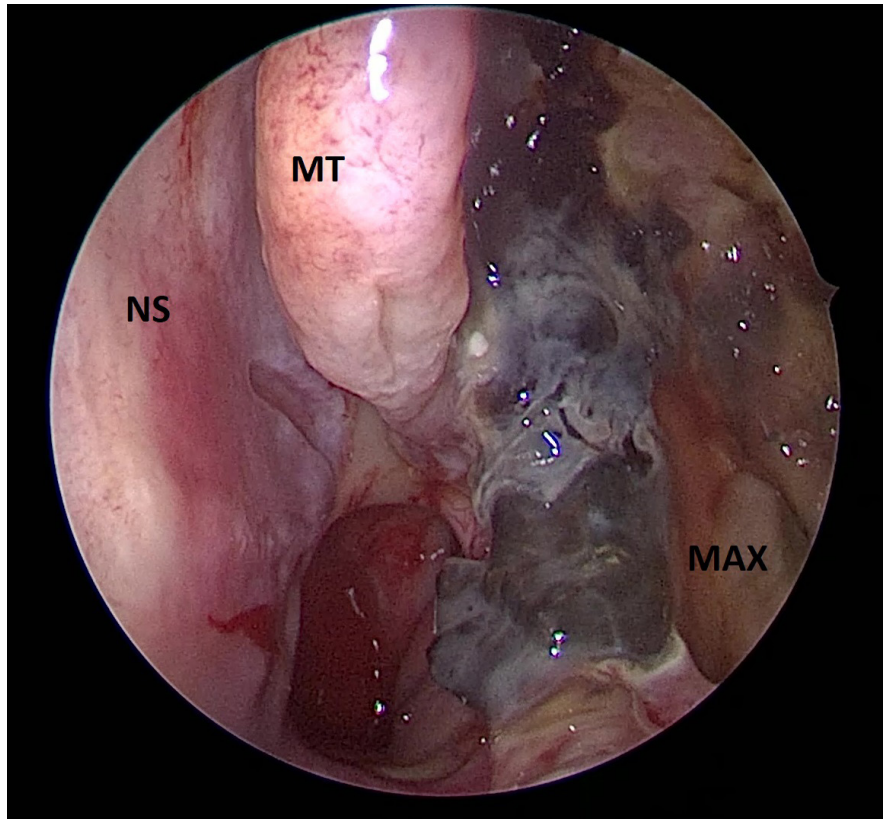

Figure 1. Nasal endoscopic view of the left nasal cavity of a patient with invasive fungal rhinosinusitis

Footnote - NS: Nasal septum, MT: Middle Turbinate, MAX: Maxillary sinus

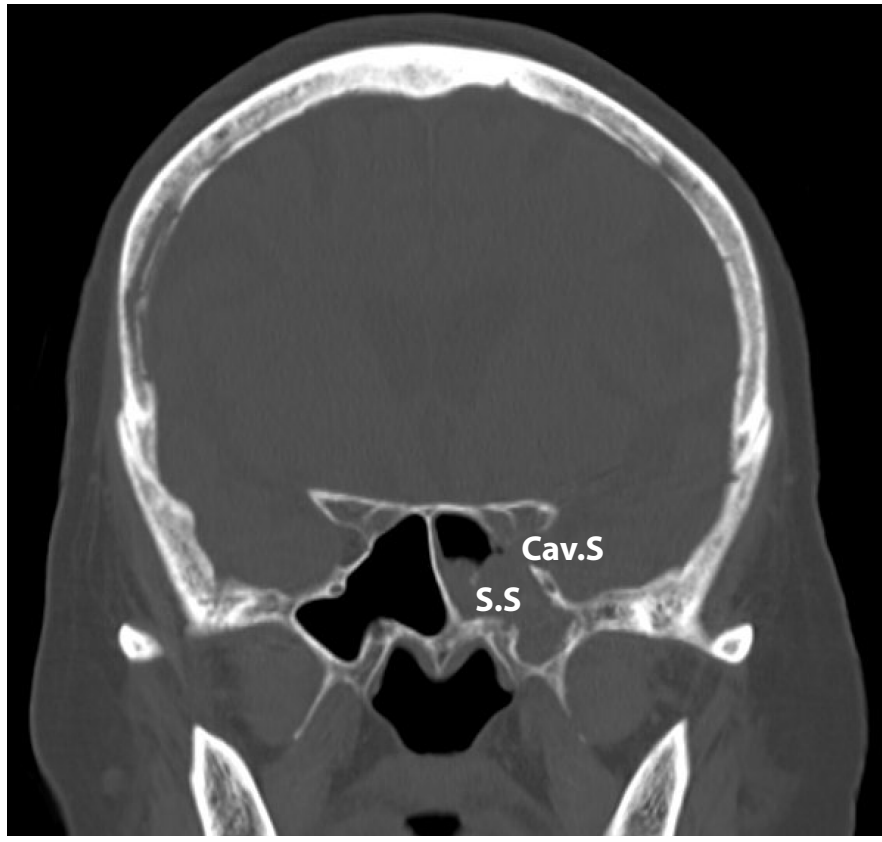

Figure 2. CT scan of a patient with invasive fungal rhinosinusitis showing cavernous sinus invasion

Footnote - S.S: Sphenoid Sinus, Cav.S: Cavernous Sinus

Table 1. Summary table of host immune response to fungi

\begin{tabular}{|c|c|c|c|c|}
\hline \multicolumn{5}{|c|}{ Innate immune response to fungi } \\
\hline \multirow{2}{*}{$\begin{array}{l}\text { Site of } \\
\text { the host }\end{array}$} & \multirow{2}{*}{ Recognition } & \multicolumn{2}{|c|}{ Normal immune response to fungus } & \multirow{2}{*}{ Diabetic patient immune response } \\
\hline & & Effector cell of the host & Response & \\
\hline \multirow{3}{*}{ 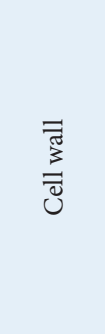 } & $\begin{array}{l}\text { Beta-glucan- } \\
\text { expression on the } \\
\text { hyphae surface }\end{array}$ & $\begin{array}{l}\text { Monocyte, Macrophage, Dendritic } \\
\text { Cell }\end{array}$ & $\begin{array}{l}\text { - Expressed effector cells of innate } \\
\text { immune system }\end{array}$ & \multirow{3}{*}{$\begin{array}{l}\text { - Decrease in production of PMN cells } \\
\text { - Decrease in chemotaxis } \\
\text { - Decrease in phagocytic activity } \\
\text { - Broken complement activation and } \\
\text { restriction } \\
\text { - Promotion of inflammation, } \\
\text { proliferation, thrombosis }\end{array}$} \\
\hline & Fungal cell wall & $\begin{array}{l}\text { - Toll-like receptors } \\
\text { C-type lectin receptor lectin-1 } \\
\text { signaling \& receptor Ligation }\end{array}$ & $\begin{array}{l}\text { - Recruitment of innate immune cells } \\
\text { - Host antimicrobial response } \\
\text { - Anti-aspergillum role - against } \\
\text { conidial germination }\end{array}$ & \\
\hline & Fungal hyphae & Dendritic cell & Expression of IL23 and TNF alpha & \\
\hline \multirow{3}{*}{ 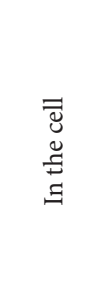 } & Resting spore & PMN cells, Neutrophil & $\begin{array}{l}\text { - Damage and degradation of fungal } \\
\text { component } \\
\text { - PMNs activate -TNF-alpha and ILs }\end{array}$ & \multirow{3}{*}{$\begin{array}{l}\text { - Decrease in neutrophil activity } \\
\text { - Inhibition of neutrophil migration } \\
\text { - Decrease in chemotaxis } \\
\text { - Decrease in phagocytic activity }\end{array}$} \\
\hline & Swollen Spore & Macrophage, Neutrophil & $\begin{array}{l}\text { Damage and degradation of fungal } \\
\text { component }\end{array}$ & \\
\hline & Fungal Hyphae & Macrophage, Neutrophil & $\begin{array}{l}\text { Damage and degradation of fungal } \\
\text { component }\end{array}$ & \\
\hline 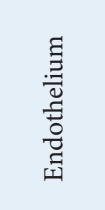 & Fungal Hyphae & $\begin{array}{l}\text { IL- } 8 \text { response in monocytes and } \\
\text { thrombin activation }\end{array}$ & $\begin{array}{l}\text { Limit in hyphae elongation and induced } \\
\text { damage of fungi }\end{array}$ & $\begin{array}{l}\text { - Activation of Protein Kinase C } \\
\text { - Decrease in vascular dilation } \\
\text { - Enhanced GRP78 expression of } \\
\text { the endothelial cells } \\
\text { - Elevated serum iron levels and } \\
\text { endothelial damage in DKA state }\end{array}$ \\
\hline
\end{tabular}


Table 1. (Continued)

\begin{tabular}{|c|c|c|c|c|}
\hline \multicolumn{5}{|c|}{ Adaptive immune response to fungi } \\
\hline $\begin{array}{l}\text { Site of } \\
\text { the host }\end{array}$ & $\begin{array}{l}\text { Immune } \\
\text { recognition }\end{array}$ & Action & Response & Diabetic patient immune response \\
\hline \multirow{4}{*}{$\begin{array}{l}\bar{\Xi} \\
\Xi \\
\Xi \\
\Xi\end{array}$} & Treg & $\begin{array}{l}\text { - Balance Th1 and Th2 } \\
\text { - Limit fungal or reduced } \\
\text { inflammatory response }\end{array}$ & Production of IL10 & \multirow{4}{*}{$\begin{array}{l}\text { - Inhibition of the IL-10 production } \\
\text { by myeloid cells } \\
\text { - Inhibition of the IFN-gamma and } \\
\text { TNF-alpha production by T cells }\end{array}$} \\
\hline & Th1 & Clearance of fungal pathogen & Production of IFN - gamma & \\
\hline & Th2 & Pathogenic & Production of IL4 & \\
\hline & Th17 & $\begin{array}{l}\text { Protective or harmful role } \\
\text { depending upon fungal loads } \\
\text { and components }\end{array}$ & Production of IL17 & \\
\hline
\end{tabular}

Abbreviations: $\mathrm{PMN}=$ polymorphonuclear cell, $\mathrm{IL}=$ Interleukin, $\mathrm{IFN}=$ Interferon, $\mathrm{TNF}=$ tumour necrosis factor

its hyperglycemic and acidity state. ${ }^{4}$ However, it is controversial whether diabetes is associated with good or poor prognostic factors of the invasive fungal rhinosinusitis. One study showed that DKA did not affect the survival outcome. ${ }^{5}$ This manuscript aims to review the existing literature regarding the immune response to fungi in diabetic patients with invasive fungal rhinosinusitis. Host immune response to fungi is summarized in Table 1.

\section{Innate immune response to fungi in normal host}

The fungal cell wall is one of the pathogen-associated molecular patterns (PAMPs) which is the first structure recognized by the immune system and activates the host immune response to the fungi. Beta-glucan is found in the fungal cell wall. Its expression on the hyphae surface is recognized and regulated by pattern recognition receptors (PRRs). These PRRs are expressed on most effector cells of the innate immune system, including on the surface of macrophages and the human monocyte derived dendritic cells. The major PRRs are Toll-like receptors (TLRs) and C-type lectin receptor, lectin-1. Cytokines and chemokine productions are induced by the signaling and receptor ligation resulting in a recruitment of innate immune cells and host antimicrobial response. The adaptive immune response is also induced. ${ }^{6}$ Rhizophus hyphae induce dendritic cells which release interleukin (IL)-23 and tumor necrosis factor alpha (TNF- $\alpha$ ). IL-23 drives $\mathrm{T}$ helper (Th) 17 responses and TNF- $\alpha$ upregulates the Th1 response. The inhibition of $\beta$-glucan receptor, Dectin- 1 reduces the IL23 production. $^{7}$

A first line protective immune response is required to get rid of the fungal spores and limit their ability to spread before an invasive fungal infection is developed. The first line defense cells such as monocytes, macrophages and natural killer cells recognize the pathogen and kill the hyphae. The first defensive response to inhaled Aspergillus spores is through the monocytes that inhibit the spores germination. Monocytes are capable of ingesting Aspergillus conidia and inducing damage to the hyphae. The anti-aspergillum role of $\mathrm{CD}_{14}{ }^{+}$and $\mathrm{CD}_{16}{ }^{+}$monocytes is against conidial germination. $\mathrm{CD}^{+} 4^{+}$and $\mathrm{CD}^{+} 6^{+}$enhance an inflammatory response by producing the TNF- $a{ }^{6}$ Macrophages, the next defense cells, localize the infection at the early stage and prime the adaptive immune response resulting in a more aggressive and specific response to the infection. ${ }^{8}$ Other first line defense cells, the natural killer cells, limit tissue damage by inducing cell cytotoxicity. If the protective response of the first line defense cells is inadequate, polymorphonuclear leukocytes (PMNs) will kill the hyphae. After Rhizopus oryzae (R. oryzae) damages endothelial cells, the interactions between $R$. oryzae and the endothelial cells induce the phagocytosis of the fungus. ${ }^{9}$ Neutrophils provide the rapid response that fight against fungal hyphae by infiltrating the infected site and timely apoptosis. ${ }^{10}$ Neutrophils can induce damage to hyphae by several means. When resting spores that are highly resistant to macrophage activity, swollen spores and hyphae are killed by non-oxidative methods and neutrophil extracellular traps (NETs) antimicrobial action kill.6,8,10 After monocyte and neutrophil attach to fungal growth, the fungi are killed by oxidative means. PMNs activate the pro-inflammatory signaling by inducing pro-inflammatory cytokines such as TNF- $\alpha$ and ILs. PMNs prevent spore germination of the fungus even if the phagocytes fail to kill the spores. As a result, the mucor is non-pathogenic in healthy persons. ${ }^{11}$ Aspergillus hyphae activate platelets which induce both the inflammatory (IL-8) response in monocytes and thrombin activation. ${ }^{6}$ Platelets can adhere to the cell walls of the Aspergillus hyphae which limit hyphae elongation and induce damage of fungi.

\section{Adaptive immune response to fungi in normal hosts}

The $\mathrm{T}$ helper (Th) cells are important for the clearance of pathogenic fungi. The Th1 response plays a protective role while the Th2 response plays a non-protective role. The role of regulatory $\mathrm{T}$ cells ( $\mathrm{T}$ regs) during fungal infection is to balance between the excessive inflammatory response due to the Th1 response and the hypersensitivity reaction associated with the Th2 response. ${ }^{12}$ The Th17 response depends upon fungal loads and components to become either a protective or harmful role. The Th1 cells produce interferon gamma (IFN- $\gamma$ ) as a protective response against fungus. The Th17 cells produce IL-17, which has a profound impact on neutrophil activity in a fungal reaction. In addition, IL-4, IL-10 and IFN- $\gamma$ are also released to fight against fungal infection. ${ }^{8}$ 
An acquired immune response is mediated by the CD4 (Th1, Th2, and Th17) and CD8 $\mathrm{T}$ cell responses.

\section{Immune deficiency in diabetes mellitus}

The reasons why patients with diabetes mellitus are more susceptible to infections are not clearly understood. Diabetes is acknowledged as a metabolic disorder and secondary immune deficiency. Hyperglycemia is the main cause of complications such as retinopathy, nephropathy and neuropathy. It is also a precipitating factor of cardiovascular complications in long standing diabetes. Activation of a protein kinase $\mathrm{C}$ (PKC) isoforms, in particular PKC-B, is the well described pathway in the development of vascular complications in patients with diabetes. ${ }^{13}$

Innate immunity of the patients with diabetes is defective in both the humoral and cellular parts. Increased glycation status reduces the expression of class I major histocompatibility complex (MHC) on the surface of myeloid cells, and inhibits the IL-10 production by myeloid cells and the IFN- $\gamma$ and TNF- $\alpha$ production by T cells. ${ }^{14}$ In addition, mononuclear cells and monocytes of patients with diabetes secrete less IL-1 and IL-6. ${ }^{15}$ The hyperglycemic state also decreases vascular dilation and the NETs formation. The structure of complement is altered which inhibits complement fixation to bacteria. Complement dependent and complement independent mechanisms induced by a high level of glucose promote inflammation, proliferation and thrombosis. In diabetes mellitus, the balance between complement activation and restriction is broken.

The major effects of the above decrease phagocytosis. ${ }^{13,16}$ Hyperglycemia activates protein kinase $C$ which inhibits neutrophil migration, decreases production of PMN cells, decreases chemotaxis and decreases phagocytic activity. ${ }^{17}$ There are many studies showing the decrease of phagocytic activities. A study by Albert et al. measured phagocytic activities of the patients with type II diabetes and showed less percentage of activated macrophages when compared to the nondiabetic patients. Another study by the same group showed that the percentage of activated polymorphonuclear cells and the phagocytic activities were significantly increased after the blood glucose was well-controlled for 5 days. ${ }^{8}$

Patients with good metabolic control showed a robust secondary immune response to standard antigens suggesting normal $\mathrm{T}$ memory cell and $\mathrm{CD} 4^{+}$lymphocyte functions. In type 1 diabetes, $\mathrm{T}$ lymphocyte function is unaffected as long as the $\mathrm{HbA1C}$ is less than $8 \mathrm{mmol} / \mathrm{l}^{18}$ Nevertheless, one study showed that adaptive immunity could be defective independent of glycaemia. There were impaired proliferative $\mathrm{CD} 4^{+}$ cell responses to primary protein antigens due to an altered expression of cellular adhesion molecules and/or reduced cytokine release. Although a well-controlled blood glucose may help to normalize cell mediated immunity in diabetic patients, there are several other factors that could affect the immunity system. ${ }^{19}$

\section{Immune response to fungi in patients with dia- betic mellitus}

Patients with DKA have elevated serum iron levels due to the release of iron from binding proteins in the presence of acidosis. ${ }^{20}$ Iron regulates endothelial cell damage. Patients with diabetes that have endothelial damage are uniquely predisposed to developing mucormycosis, especially when the basement membrane and extracellular matrix proteins were exposed. Fungi are normal commensals in the diseased sinus area. The main infectious particles for mucormycosis are asexual spongiospores. There are three types of spores: resting spores, swollen spores, and opsonized spores. These resting spores can swell and germinate to produce fast-growing hyphae during their natural life cycle. Germination and filamentous growth within a host cause angioinvasion, vessel thrombosis, and necrosis. ${ }^{21}$ Angioinvasion is a hallmark of zygomycotic infections. Hyperglycemia but not hyperosmolarity is responsible for the enhanced human glucose-regulated protein-78 (GRP78) expression. When endothelial cells were incubated at the $\mathrm{pH}$ values similar to those seen in the patients with DKA, the GRP78 expression of the endothelial cells was significantly enhanced in the lower $\mathrm{pH}$ values compared with the normal blood $\mathrm{pH}$ of 7.4..$^{22}$ The GRP78 on intact endothelial cells binds to Mucorales germlings. Iron and the overexpression of glucose-induced GRP78 enhance endothelial cell susceptibility to $R$. oryzae-induced fungal invasion and damage. Of importance, the anti-GRP78 blocked this enhanced endothelial cell susceptibility to $R$. oryzae-induced damage. ${ }^{22}$

\section{Discussion}

Overall, invasive fungal rhinosinusitis has a wide range of mortality rates from $20 \%$ to $80 \%{ }^{23,24}$ The extension of the fungal tissue invasion is the key risk factor affecting the mortality rate. Intracranial involvement is acknowledged as a poor prognostic factor with a $73.5 \%$ mortality rate. ${ }^{25}$ Further, underlying conditions of the patients that impaired their immune function are the other key contributing factors. If the immunocompromised state of the patients becomes well-controlled and the immune function recovers, the mortality and the morbidity rate should be minimized. The morbidity rate varies from $20 \%$ to $50 \%$, which includes $20 \%$ of the patients that need orbital exenteration. ${ }^{23}$

Compared to other immunosuppressive conditions, diabetes mellitus is acknowledged as an underlying disease related to a higher mortality and morbidity rate. ${ }^{26}$ A Korean study reported that all the fatal cases $(100 \%)$ of rhinocerebral mucormycosis were diabetic and $50 \%$ of them had DKA, ${ }^{27}$ athough this being controversial. In contrast, a study by Saedi et al. ${ }^{28}$ reported a greater survival rate for diabetes mellitus $(70.6 \%)$ than for hematologic malignancy $(40 \%)$. The diversity of treatment outcomes found within a study and across studies could be explained by a great variety of the immune status of diabetic patients. Understanding the immune response to fungi in diabetic patients is essential. Associations between the immunopathology of diabetes, the pathophysiology of fungal infections and the therapeutic outcomes must be considered in practice. Treatment should aim for 
controlling the underlying conditions and a restoration of the immune function.

The findings from our review showed that fungal cell walls activated a system of pattern recognition receptors resulting in both innate and adaptive immune responses. However, a recruitment of innate immune cells and adaptive immune response in patients with diabetes were defective. Hyperglycemia reduced the expression of the class I major histocompatibility complex, decreased vascular dilation and decreased the formation of neutrophil extracellular traps. The activation of protein kinase $\mathrm{C}$ inhibited neutrophil migration, decreased production of polymorphonuclear cells, decreased chemotaxis and decreased phagocytic activity. The structure of complement was altered which inhibited the complement fixation to bacteria. Patients with DKA had elevated levels of serum iron which regulated endothelial cell damage. Iron and the overexpression of glucose-induced glucose-regulated protein 78 enhanced the susceptibility of endothelial cells to fungi, and induced fungal invasion and damage. In clinical practice, hyperglycemia and ketoacidosis must be evaluated in patients with diabetes. The complement system, serum neutropenia and CD4 level should be assessed.

\section{Conclusions}

Associations between the immunopathology of diabetes, the pathophysiology of fungal infection and the therapeutic outcomes must be considered in clinical practice. In diabetic patients, both the humoral and cellular immune responses of the innate and adaptive immunity were defective. Treatment should aim for a restoration of the immune function.

\section{Acknowledgement}

The authors wish to thank The $100^{\text {th }}$ Anniversary Chulalongkorn University for Doctoral Scholarship and The $90^{\text {th }}$ Anniversary of Chulalongkorn University Research Scholarship. The authors would like to acknowledge Professor Maung Maung Khaing for his technical advice.

\section{Conflict of interest}

- Joaquim Mullol is member of advisory boards, has received speaker fees, and/or research grants from GSK, Mylan-Meda Pharma, MSD, Novartis, Optinose, SanofiGenzyme \& Regeneron, Mitsubishi-Tanabe, Menarini, AstraZeneca, and Uriach Group.

- Kornkiat Snidvongs received Honoraria for speaking at symposia from Merck Sharp \& Dohme, and Menarini

- Thwe Phyo Kan Nyunt has no conflict of interest.

\section{Authors contribution}

- Thwe Phyo Kan Nyunt search, study selection, data collection, drafting the article, and final approval

- Joaquim Mullol: expert opinion, revising the article, and final approval.

- Kornkiat Snidvongs: conception, data collection, drafting the article, and final approval

\section{References}

1. Templeton SP, Rivera A, Hube B, Jacobsen ID. Editorial: Immunity to Human Fungal Pathogens: Mechanisms of Host Recognition, Protection, Pathology, and Fungal Interference. Front Immunol. 2018;9:2337.

2. Petrikkos G, Skiada A, Lortholary O, Roilides E, Walsh TJ, Kontoyiannis DP. Epidemiology and Clinical Manifestations of Mucormycosis. Clin Infect Dis. 2012;54(Suppl 1):S23-34.

3. Latgé JP. Aspergillus fumigatus and aspergillosis. Clin Microbiol Rev. 1999;12(2):310-50.

4. Suslu AE, Ogretmenoglu O, Suslu N, Yucel OT, Onerci TM. Acute invasive fungal rhinosinusitis: our experience with 19 patients. Eur Arch Otorhinolaryngol. 2009;266(1):77-82.

5. Bhansali A, Bhadada S, Sharma A, Suresh V, Gupta A, Singh P, et al. Presentation and outcome of rhino-orbital-cerebral mucormycosis in patients with diabetes. Postgrad Med J. 2004;80(949):670-4.

6. Chai LY, Vonk AG, Kullberg BJ, Netea MG. Immune response to Aspergillus fumigatus in compromised hosts: from bedside to bench. Future Microbiol. 2011;6(1):73-83.

7. McCormick A, Heesemann L, Wagener J, Marcos V, Hartl D, Loeffler J, et al. NETs formed by human neutrophils inhibit growth of the pathogenic mold Aspergillus fumigatus. Microbes Infect. 2010;12(12-13):928-36.

8. Lecube A, Pachon G, Petriz J, Hernandez C, Simo R. Phagocytic activity is impaired in type 2 diabetes mellitus and increases after metabolic improvement. PLoS One. 2011;6(8):e23366.

9. Ibrahim AS, Spellberg B, Avanessian V, Fu Y, Edwards JE Jr. Rhizopus oryzae adheres to, is phagocytosed by, and damages endothelial cells in vitro. Infect Immun. 2005;73(2):778-83.

10. Waldorf AR, Levitz SM, Diamond RD. In vivo bronchoalveolar macrophage defense against Rhizopus oryzae and Aspergillus fumigatus. J Infect Dis. 1984;150(5):752-60.

11. Chamilos G, Ganguly D, Lande R, Gregorio J, Meller S, Goldman WE, et al. Generation of IL-23 producing dendritic cells (DCs) by airborne fungi regulates fungal pathogenicity via the induction of $\mathrm{T}(\mathrm{H})-17$ responses. PLoS One. 2010;5(9):e12955.

12. Sales-Campos H, Tonani L, Cardoso CRB, Kress MRVZ. The immune interplay between the host and the pathogen in Aspergillus fumigatus lung infection. Biomed Res Int. 2013;2013:693023.

13. King GL. The role of inflammatory cytokines in diabetes and its complications. J Periodontol. 2008;79(8 Suppl):1527-34.

14. Price CL, Hassi HOSA, English NR, Blakemore AIF, Stagg AJ, Knight SC. Methylglyoxal modulates immune responses: relevance to diabetes. J Cell Mol Med. 2010;14(6B):1806-15.

15. Geerlings SE, Hoepelman AI. Immune dysfunction in patients with diabetes mellitus (DM). FEMS Immunol Med Microbiol. 1999;26(3-4): 259-65.

16. Jafar N, Edriss H, Nugent K. The Effect of Short-Term Hyperglycemia on the Innate Immune System. Am J Med Sci. 2016;351:201-11.

17. Casqueiro J, Casqueiro J, Alves C. Infections in patients with diabetes mellitus: A review of pathogenesis. Indian J Endocrinol Metab. 2012;16 (Suppl 1):S27-36.

18. Eibl N, Spatz M, Fischer GF, Mayr WR, Samstag A, Wolf HM, et al. Impaired primary immune response in type-1 diabetes: results from a controlled vaccination study. Clin Immunol. 2002;103(3 Pt 1):249-59.

19. Lapolla A, Tonani R, Fedele D, Garbeglio M, Senesi A, Seraglia R, et al. Non-enzymatic glycation of IgG: an in vivo study. Horm Metab Res. 2002;34(5):260-4.

20. Schell WA. Unusual fungal pathogens in fungal rhinosinusitis. Otolaryngol Clin North Am. 2000;33(2):367-73.

21. Frater JL, Hall GS, Procop GW. Histologic features of zygomycosis: emphasis on perineural invasion and fungal morphology. Arch Pathol Lab Med. 2001;125(3):375-8.

22. Liu M, Spellberg B, Phan QT, Fu Y, Fu Y, Lee AS, et al. The endothelial cell receptor GRP78 is required for mucormycosis pathogenesis in diabetic mice. J Clin Invest. 2010;120(6):1914-24.

23. Turner JH, Soudry E, Nayak JV, Hwang PH. Survival outcomes in acute invasive fungal sinusitis: a systematic review and quantitative synthesis of published evidence. Laryngoscope. 2013;123(5):1112-8.

24. Cho HJ, Jang MS, Hong SD, Chung SK, Kim HY, Dhong HJ. Prognostic factors for survival in patients with acute invasive fungal rhinosinusitis. Am J Rhinol Allergy. 2015;29(1):48-53.

25. Sun HY, Forrest G, Gupta KL, Aguado JM, Lortholary O, Julia MB, et al. Rhino-orbital-cerebral zygomycosis in solid organ transplant recipients. Transplantation. 2010;90(1):85-92. 


\section{APJAI}

26. Payne SJ, Mitzner R, Kunchala S, Roland L, McGinn JD. Acute Invasive Fungal Rhinosinusitis: A 15-Year Experience with 41 Patients. Otolaryngol Head Neck Surg. 2016;154(4):759-64.

27. Jung SH, Kim SW, Park CS, Song CE, Cho JH, Lee JH, et al. Rhinocerebral Mucormycosis: consideration of prognostic factors and treatment modality. Auris Nasus Larynx. 2009;36(3):274-9.
28. Saedi B, Sadeghi M, Seilani P. Endoscopic management of rhinocerebral mucormycosis with topical and intravenous amphotericin B. J Laryngol Otol. 2011;125(8):807-10. 